\title{
MR findings of primary ovarian granulosa cell tumor with focus on the differentiation with other ovarian sex cord-stromal tumors
}

\author{
He Zhang ${ }^{1 \dagger}$, Hongyu Zhang ${ }^{2 \dagger}$, Shouxin Gu', Yanyu Zhang ${ }^{1}$, Xuefen Liu ${ }^{1}$ and Guofu Zhang ${ }^{1,3^{*}}$
}

\begin{abstract}
Background: To describe magnetic resonance imaging (MRI) features of ovarian granulosa cell tumors (OGCTs) and compare with other sex cord-stromal tumors (OSCs) in ovary.

Methods: MR findings of 18 patients with surgically confirmed ovarian granulosa cell tumor were retrospectively reviewed by two radiologists with consensus reading. All MR examinations were prospectively performed within one month. Clinical and imaging characteristics of OGCTs were evaluated and compared with OSCs (control group).

Results: In 18 patients, 20 ovarian granulosa cell tumors were detected on MRI. Sixteen tumors appeared as solid or mostly solid mass (16/20), while 4 tumors as cystic mass. Pathological pelvic fluid was detected in 1 OGCT $(1 / 18)$ and 11 OSCs (11/34) $(p=0.031)$.On T2 weighted imaging (T2WI), most of OGCTs displayed hyperintense signal and mixed signal (19/20); on T1 weighted imaging (T1WI), 11 OGCTs (11/20) displayed similar signal as on T2WI imaging. The lesion signal between OGCT and OSC differed significantly on both T1WI $(p=0.017)$ and T2WI $(p=0.002)$. Tumoral bleeding was detected in 6 OGCTs on MRI. On diffusion weighted imaging (DWI) images, OGCTs mostly appeared as high signal (16/20). Average apparent diffusion coefficient (ADC) value derived from DWI images in the OGCT group $\left(0.84 \pm 0.26 \times 10^{-3} \mathrm{~mm}^{2} / \mathrm{s}\right.$ was less than the control group $\left(1.22 \pm 0.47 \times 10^{-3} \mathrm{~mm}^{2} / \mathrm{s}\right)$ with statistical difference $(p=0.002)$.
\end{abstract}

Conclusions: MRI could provide important information in OGCT diagnosis. ADC value might be useful in differentiating OGCT from OSC.

Keywords: Ovarian granulosa cell tumor, Sex-cord tumor, MRI, Diagnostic imaging

\section{Background}

Ovarian granulosa cell tumor (OGCT) is a rare sex cord-stromal tumor in ovary, accounting only $2-3 \%$ of all ovarian tumors [1]. Pathologically, OGCTs are classified into two subtypes: adult and juvenile form, in which adult type occupying 95\% of all OGCTs [2]. Despite OGCT have a favorable prognosis, an incidence of $25-30 \%$ metastases or recurrences make it as a low malignant potential ovarian tumor [3]. Chemotherapy is recommended as adjuvant treatment for patients

\footnotetext{
* Correspondence: dr.zhanghe@yahoo.com

${ }^{+}$He Zhang and Hongyu Zhang contributed equally to this work.

'Department of Radiology, Obstetrics and Gynecology Hospital, Fudan

University, Shanghai 200011, People's Republic of China

${ }^{3}$ Institute of functional and molecular medical imaging, Fudan University,

Shanghai 200040, People's Republic of China

Full list of author information is available at the end of the article
}

with stages II-IV granulosa cell tumor [4-7]. Owing to the superb soft-tissue resolution and free radiation, magnetic resonance imaging (MRI) is widely used as a problem-solving modality in assessment of complex adnexal masses that are indeterminate on ultrasonography (US) or computed tomography (CT) [8]. Till now, most of reported OGCTs in the literatures are published as case report and no detailed MRI knowledges of OGCTs have been comprehensively described [6-13]. In this study, by evaluating OGCTs in our single institution, we aimed to: (1) thoroughly evaluate the MRI appearances of OGCTs in a large cohort of samples and record ADC values for each lesion; (2) compare these features with OSCs.

(c) The Author(s). 2018 Open Access This article is distributed under the terms of the Creative Commons Attribution 4.0 International License (http://creativecommons.org/licenses/by/4.0/), which permits unrestricted use, distribution, and reproduction in any medium, provided you give appropriate credit to the original author(s) and the source, provide a link to the Creative Commons license, and indicate if changes were made. The Creative Commons Public Domain Dedication waiver (http://creativecommons.org/publicdomain/zero/1.0/) applies to the data made available in this article, unless otherwise stated. 


\section{Methods}

\section{Study subjects}

Between December 2009 and December 2015, 1217 consecutive patients with clinically suspected adnexal disease prospectively underwent $1.5 \mathrm{~T}$ MRI examinations before pelvic or laparoscopic surgery at our institution. The time interval between the MRI evaluation and surgery was less than one month (2-27 days; mean, $5 \pm 12$ days).

Among them, 18 patients with histologically proven OGCT (24-79 years of age; average age, $45.9 \pm 15.3$ years) were included in this study when we retrospectively retrieved the database on the Picture Archiving and Communication System (PACS). Two recurrent OGCTs were excluded for further analysis because the primary imaging data was evaluated in another hospital. Thirty four patients with OSCs, including histologically proven sclerosing stroma tumors (SST, $n=4)$, fibrothecomas $(n=21)$, and fibromas $(n=9)$, were included as the comparative group. Patients with any previous pelvic surgery or radiation history were arbitrarily excluded because the inherent structure of the uterus may has been altered. Details of the samples studied are summarized in Table 1.

\section{Image acquisition}

MRI was performed using a 1.5-T MR system (Magnetom Avanto, Siemens, Erlangen, Germany) with a phased-array coil. The routine MRI protocols used for assessment of pelvic masses included axial turbo spin-echo (TSE) T1WI, sagittal TSE T2WI, and axial/sagittal TSE fat-suppressed T2WI (FS T2WI). For axial images, the transverse plane was perpendicular to the long axis of uterine body; for sagittal images, the longitudinal plane was parallel to the main body of uterus. DWI using an echo-planar imaging two-dimensional (EP2D) sequence performed in the axial plane with parallel acquisition technique by using $b$ value $=0,100$, and $800 \mathrm{~s} / \mathrm{mm}^{2}$. Contrast-enhanced pelvic imaging was acquired at multiple phases of contrast medium enhancement in both sagittal and axial planes.

\section{Image analysis}

The location, size (the largest dimension in two orthogonal planes), margin (regular or irregular); visibility of hemorrhagic component (high signal on T1WI) within

Table 1 Summaries of histological results in 54 ovarian sex-cord lesions detected on MRI in 52 patients

\begin{tabular}{ll}
\hline Pathology diagnosis & Numbers \\
\hline Granulosa cell tumor & $20^{\text {a }}$ \\
Fibrothecoma & 21 \\
Sclerosing stroma tumor & 4 \\
Fibroma & 9
\end{tabular}

${ }^{\text {andicates }} 20$ lesions in 18 patients the lesion; and presence of capsule, pelvic-free fluid and lymph node were also noted. On T1WI, hypo-, iso-, and hyperintensity were similar for the pelvic fluid, pelvic wall muscle, and fat signal; on T2WI, hypo-, iso-, and hyperintensity were similar for the pelvic bone, pelvic wall muscle, and fat signal; on $b=800 \mathrm{~mm}^{-2} / \mathrm{s}$ DWI images, the low, intermediate, and high-signal intensity were similar for the pelvic bone, myometrium, and endometrium. After the intravenous injection of the contrast medium, the lesion enhancement type was graded as follows: 1, minor enhancement (clearly less than the myometrium); 2, mild enhancement (less than the myometrium); 3, moderate enhancement (similar to the myometrium); or 4 , avid enhancement (more than the myometrium). ADCs were measured manually on post-processing workstation (Leonardo, Siemens, Germany) by one reviewer (H.Z.). Two observers (S. X. G. and H.Z., with 6 and 10 years of experience in gynecological imaging, respectively), who were blinded to the histological results independently, analyzed MRI datasets of each participant. At the end of the study, two observers were also required to determine the tumor etiology (benign or malignant) according to previous established criteria [14-16]. For interobserver discrepancies in the evaluation of uterine lesions, consensus was achieved.

\section{Statistical analyses}

Continuous variables were expressed as the means \pm standard deviation (S.D.) and compared with the unpaired $t$ test if normally distributed or the Mann-Whitney test if not normally distributed. A nonparametric test (Mann-Whitney) was used to test other nonparametric variables within each group. The area under the receiver operating characteristic (ROC) curve (AUC) was calculated for ADCs to discriminate OGCTs from OSCs. SPSS (version 13.0, SPSS, Chicago, USA) was used to perform statistical analyses. $P$ values $\leq 0.05$ were considered statistically significant.

\section{Results}

The histological results revealed 20 OGCTs in 18 patients (24-79 years of age; average age, 48.2 \pm 15.1 years), including 17 adult types and 1 juvenile type (Fig. 1). Laparotomy was performed in 13 patients while others with laparoscopic surgery. Nine patients had regular or irregular menses, while menopause in nine patients. According to the international federation of obstetrics and gynecology (FIGO) staging system [17], twelve patients were classified as Ia, 4 as Ic, 1 as IIIa and 1 as IIIc. All primary tumors were solitary lesion detected on MRI, except for three primary lesions in one patient at initial evaluation (Fig. 2). Most of OGCTs at presentation appeared as the large mass with the average diameter of $9.33 \pm 5.43 \mathrm{~mm}$. Among them, five patients were 

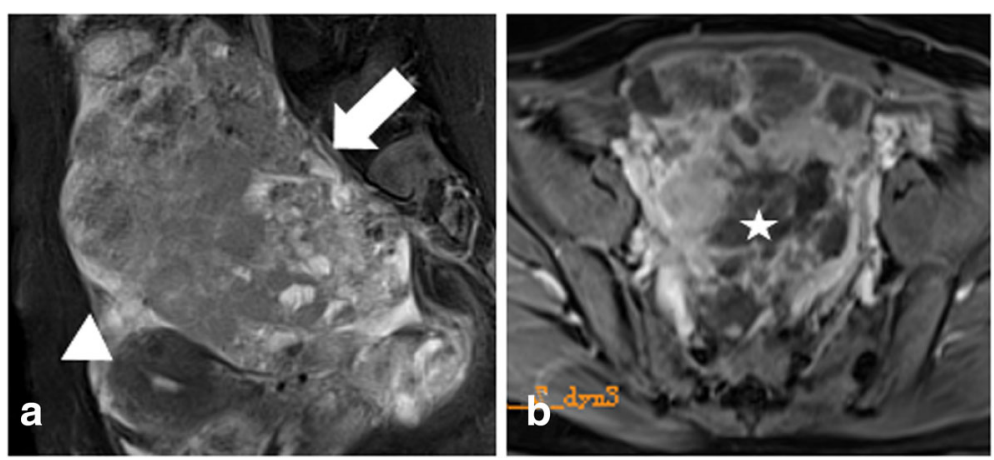

Fig. 1 A 32-year-old woman histologically proved OGCT in juvenile type (IIIC). On sagittal FS-T2WI image (a), the giant mass with irregular margin (arrow) occupy the majority of pelvis with the uterus being pushed forwardly (arrow head). (b) On contrast-enhanced images, the mass show homogeneously moderate enhancement; the necrotic area do not show enhancement (star)

also accompanied by other ovarian etiologies, including endometrial polyps $(n=2)$, uterine fibroids $(n=2)$, follicular cyst $(n=1)$, Brenner tumor $(n=1)$ and fibroid and mucinous cystadenoma $(n=1)$. Vaginal discharge was recorded in one OG patient. The details of baseline characteristics for all studied samples are summarized in Table 2.

\section{MRI characteristics}

In this studied samples, OGCTs showed varying signal intensities on both T1WI and T2WI images. On T1WI, OGCTs showed various signal from low to mixed signal, which was different to OSCs mostly appearing as hypointense and isointense mass $(p=0.017)$. On T2WI, OGCTs mainly displayed as high and mixed signal (19/20).
Accordingly, OSCs mainly displayed as isointense (12/34) and hyperintense signal intensity (10/34) on T2WI images.

Neoplastic bleeding can be seen in six OGCTs, appearing as the patchy high signal intensity on T1WI images in the tumor body (Fig. 3), which was not identified in OSC group $(p=0.000)$. Seventeen OGCTs were round or oval masses with regular margin $(17 / 20)$ and intact capsule (16/20), while $33(33 / 34)$ and 34(34/34) observed in OSCs, respectively $(p=0.015)$. Regarding the tumor component, OGCTs mostly appeared as the solid or mostly solid component (16/20, Fig. 4), while OSCs always showed purely solid component $(28 / 34)(p=0.000)$. On the post-contrast images, fourteen lesions $(14 / 20)$ in OGCT group displayed mild enhancement and six

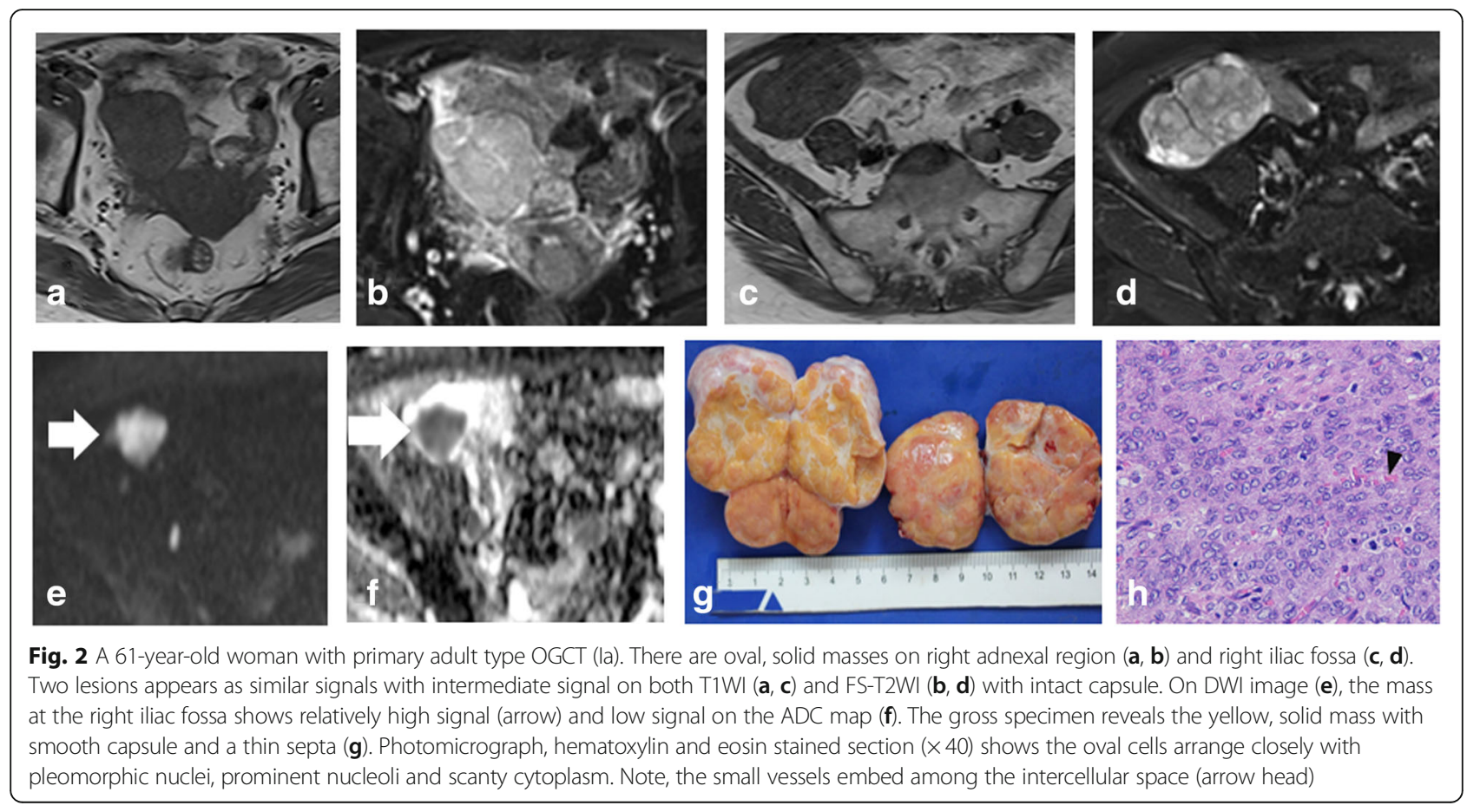


Table 2 Basic and imaging characteristics of OGCTs

\begin{tabular}{|c|c|c|c|c|}
\hline & OGCTs & OSCs & $P$ value & $O R^{a}$ \\
\hline \multicolumn{5}{|l|}{ Imaging findings } \\
\hline T1 signals & 20 & 34 & 0.017 & \\
\hline hypointensity & 4 & 8 & & \\
\hline isointensity & 5 & 26 & & \\
\hline hyperintensity & 5 & & & \\
\hline mixed & 6 & & & \\
\hline T2 signals & & & 0.002 & \\
\hline hypointensity & & 5 & & \\
\hline isointensity & 1 & 12 & & \\
\hline hyperintensity & 12 & 10 & & \\
\hline mixed & 7 & 7 & & \\
\hline DWI signals & & & 0.003 & \\
\hline hypointensity & 1 & 7 & & \\
\hline isointensity & 3 & 11 & & \\
\hline hyperintensity & 16 & 16 & & \\
\hline \multicolumn{5}{|l|}{ mixed } \\
\hline Margin & & & 0.326 & 0.172 \\
\hline Regular/lregular & $17 / 3$ & $33 / 1$ & & \\
\hline Capsule & & & 0.015 & 0.800 \\
\hline Present/Absent & $16 / 4$ & $34 / 0$ & & \\
\hline Hemorrhage & & & 0.001 & 3.429 \\
\hline Present/Absent & $6 / 14$ & $0 / 34$ & & \\
\hline Component & & & 0.000 & 2.50 \\
\hline $\begin{array}{l}\text { Solid(80-100\% solid } \\
\text { component) }\end{array}$ & 8 & 28 & & \\
\hline $\begin{array}{l}\text { Cyst (80-100\% cystic } \\
\text { component) }\end{array}$ & 4 & 1 & & \\
\hline $\begin{array}{l}\text { Solid with cystic } \\
\text { changes (others) }\end{array}$ & 8 & 5 & & \\
\hline $\begin{array}{l}\text { Enhancement } \\
\text { (homogeneous/inhomogeneous) }\end{array}$ & & & 0.034 & \\
\hline minor & & $16(16 / 0)$ & & \\
\hline mild & $14(12 / 2)$ & 10(7/3) & & \\
\hline moderate & $6(5 / 1)$ & $4(4 / 0)$ & & \\
\hline avid & & $4(1 / 3)$ & & \\
\hline Maximum diameter (mm) & $9.33 \pm 5.43$ & $8.5 \pm 8.9$ & 0.753 & \\
\hline$<5$ & 6 & 17 & & \\
\hline $5-10$ & 9 & 12 & & \\
\hline$>10$ & 5 & 5 & & \\
\hline $\operatorname{ADC}$ values $\left(\times 10^{-3} \mathrm{~s} / \mathrm{m}^{2}\right)$ & $\begin{array}{l}817 \pm 144 \\
(558-1120)\end{array}$ & $\begin{array}{l}1223 \pm 473 \\
(460-2230)\end{array}$ & 0.002 & \\
\hline Septa & & & 0.121 & \\
\hline Present/Absent & $6 / 14$ & $5 / 29$ & & \\
\hline Lymph node & & & 0.913 & \\
\hline Present/Absent & $0 / 18$ & $0 / 34$ & & \\
\hline
\end{tabular}

Table 2 Basic and imaging characteristics of OGCTs (Continued)

\begin{tabular}{lllll}
\hline & OGCTs & OSCs & $P$ value & $\mathrm{OR}^{\mathrm{a}}$ \\
\hline Pelvic fluid & & & 0.031 & 8.130 \\
$\quad$ Physiological/ Pathological & $17 / 1$ & $23 / 11$ & & \\
Clinical findings & & & \\
Age(years) & $\begin{array}{l}48.2 \pm 15.1 \\
(24-79)\end{array}$ & $\begin{array}{l}54.8 \pm 15.0 \\
(21-81)\end{array}$ & 0.139 \\
Vaginal discharge/bleeding & 1 & 0 & 0.106 \\
$\begin{array}{l}\text { Menstruation } \\
\quad \text { Regular(irregular) }\end{array}$ & $9(4)$ & $18(5)$ & 0.607 \\
$\quad$ Menopause & 9 & 16 & \\
Accompanying lesions & & & 0.280 \\
$\quad$ Yes/ No & $7 / 12$ & $9 / 25$ & \\
\hline aldicates odds ratio & & &
\end{tabular}

Indicates odds ratio

showed moderate enhancement. In OSC group, most of fibromas showed minor enhancement and 4 SSTs appeared inhomogeneously avid enhancement (Fig. 5). On DWI images, $80 \%$ of OGCTs $(16 / 20,80.0 \%)$ showed high signal intensities in comparison with $47 \%(16 / 34$, $47.1 \%)$ in OCS group. The average ADC value $(817 \pm$ $\left.144 \times 10^{-3} \mathrm{~s} / \mathrm{m}^{2}\right)$ in OGCT group was obviously less than OSC group $\left(1223 \pm 473 \times 10^{-3} \mathrm{~s} / \mathrm{m}^{2}, p=0.002\right)$ and fibrothecoma $\left(1209 \pm 437 \times 10^{-3} \mathrm{~s} / \mathrm{m}^{2}, p=0.001\right.$, Fig. 6). When use the ADC cutoff value as $619 \times 10^{-3} \mathrm{~s} / \mathrm{m}^{2}$, MRI could yield a sensitivity of $79.4 \%$ and a specificity of $60.0 \%$ for diagnosis of OGCT, respectively; the AUC is $0.784(95 \%$ CI:0.658-0.910) (Fig. 7). Enlarged lymph nodes were not observed in all OGCTs at MRI images. Pathological fluid was only noted in one OGCT, obviously less than 11 cases in OSCs group. At multivariate analysis, neoplastic hemorrhagic contents (OR: 3.429), component (OR: 2.50) and no pathological fluid (OR: 8.130) are more indicative of OGCT diagnosis (Table 2). On MRI, two readers accurately determined the malignant condition in 17 cases. If combining ADC values, then they could yield a sensitivity of $95.0 \%$ and a specificity of $94.1 \%$ for OGCT diagnosis. Three lesions were misdiagnosed as uterine fibroids and two lesion as fibrothecoma before invasive procedures. The overall diagnostic performance of MRI for diagnosing OGCT is listed as Table 3.

\section{Discussion}

OGCTs account for less than $5 \%$ of all malignant ovarian tumors, representing the most common malignant sex cord-stromal tumor in ovary origin; clinically, it may require additional chemotherapy after tumor removal surgery [13]. Radiological knowledge of this rare ovarian tumor is still limited in the reported literature, especially focusing on MR acquisition. Herein, we collected 20 OGCTs in 18 patients with prospective MR 

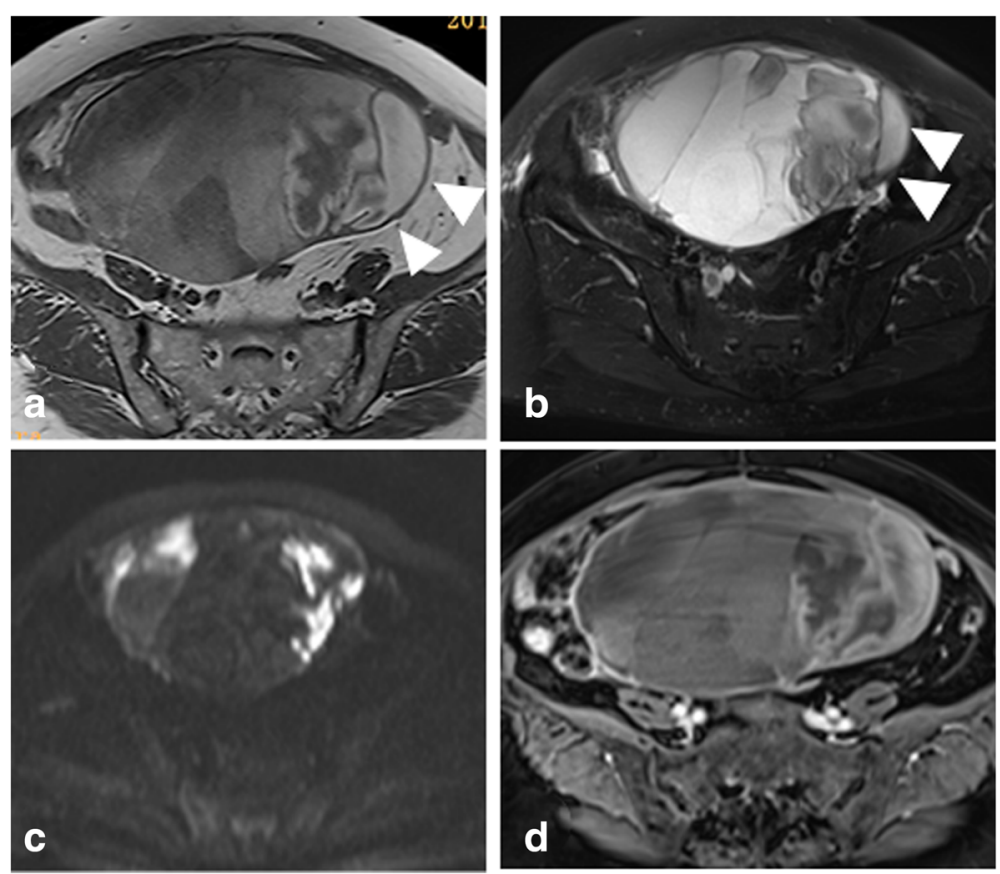

Fig. 3 A 54 -year-old woman with primary adult type OGCT (Ic). The mass shows as the purely cystic lesion with mostly high signal on T1WI (a) and T2WI (b). Note, the hemorrhagic contents locates on the left side of the tumor, representing the relatively high signal on T1WI and low signal on T2WI (arrowhead) and high signal on DWI (c). After injection of contrast medium, the cystic wall shows minor enhancement (d)
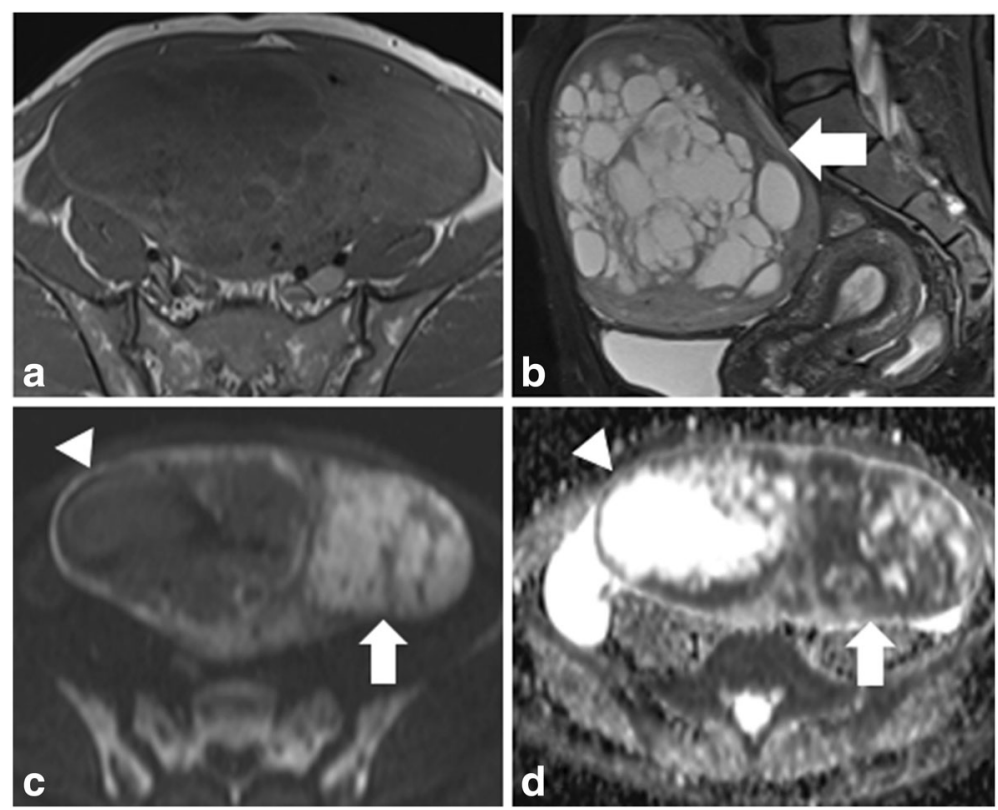

Fig. 4 A 50-year-old woman with primary adult type OGCT (IIla). (a) The spongelike changes (arrowhead) are observed in the interior of the tumor appearing as the mostly solid mass (b). The cystic contents (arrowhead) give the low signal on DWI (c) and relatively high signal on ADC map (d), while the solid part (arrow) with the relatively high signal on DWI and low signal on ADC map 

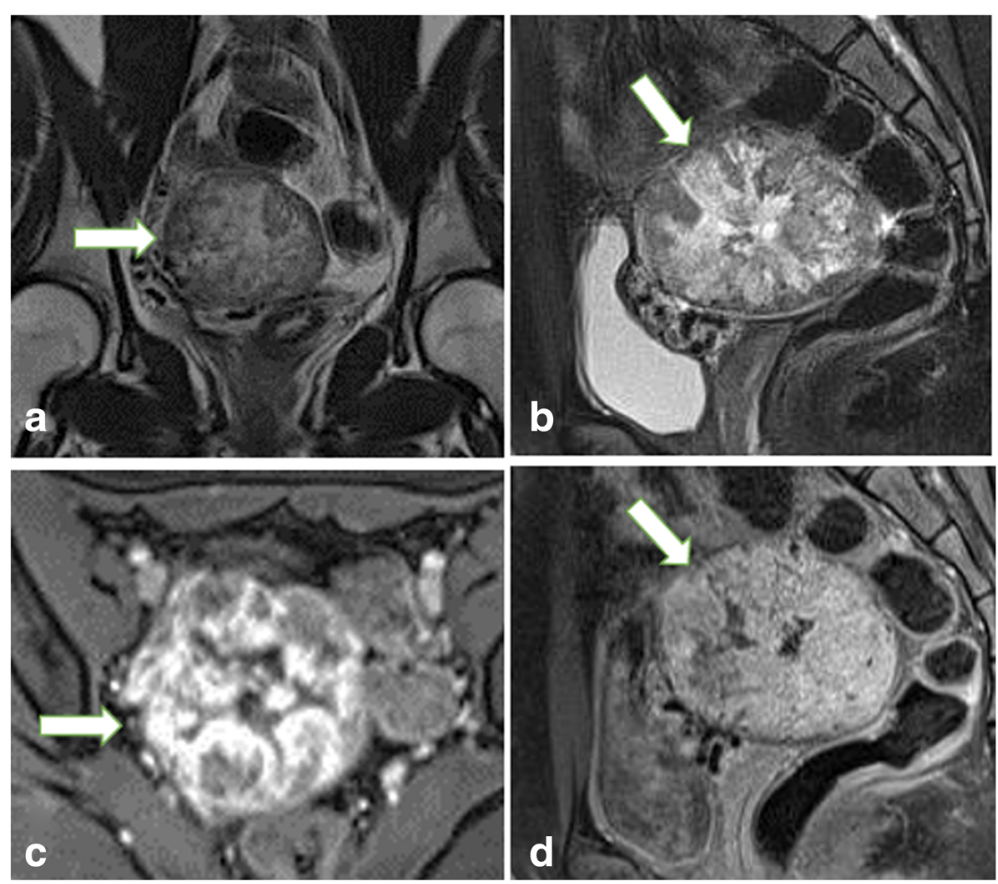

Fig. 5 An 18-year-old woman with histological proven SST at the right ovary. On coronal T2WI (a) and sagittal FS-T2WI (b), the solid mass (arrow) appears as the "comb" sign with centrally hyperintense signal surrounded by peripherally isointense signal. After injection of the contrast medium, the mass shows flush-in on early stage enhancement (c) and flush-out effect on late stage postcontrast image (d)

acquisition data at our single institution within nearly 10 years. To the best of our knowledge, this is the first study to describe the detailed MRI characteristics in the largest OGCT samples.

Owing to production of estrogen, OGCTs can be associated with endometrial hyperplasia, polyps, and carcinoma [18]. In our studied samples, we did observe endometrial

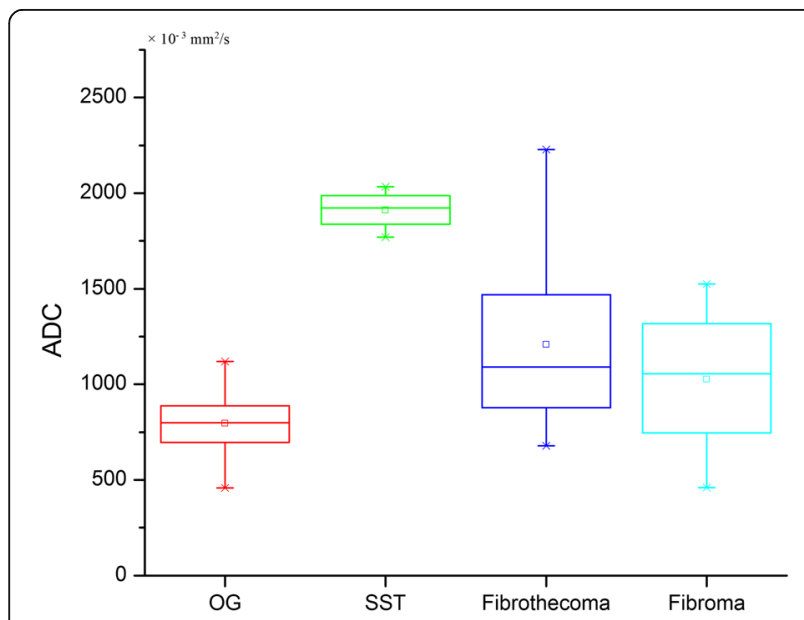

Fig. 6 Stem-and-Leaf Plots of the calculated ADC values $\left(10^{-3} /\right.$ $\mathrm{mm}^{2} / \mathrm{s}$ ) within four groups. The mean ADC value in OGCT is lower than that in other three groups $(p=0.002)$ with some overlap with fibrothecoma and fibroma polyps in two patients and vaginal bleeding in one patient. All other accompanied lesions were incidentally detected on MRI. In terms of tumor component, OGCTs appeared as purely solid $(8 / 20)$ to entirely cystic (4/22) mass with various morphology. Our findings are in accordance with the literature that OGCTs has more heterogeneity than OSCs. It is reported that a spongelike, multilocular cystic

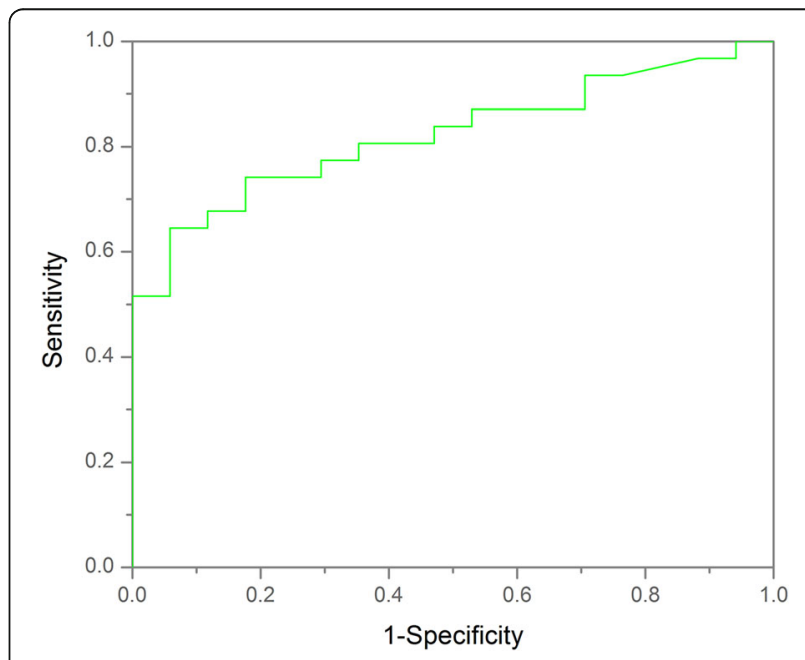

Fig. 7 The diagnostic performance of ADC value in discriminating OGCT from OSC 
Table 3 Diagnostic performance of MRI in diagnosis OGCTs according to two reading protocols

\begin{tabular}{llllll}
\hline Protocol & SEN (\%) & SPE (\%) & PPV (\%) & NPV (\%) & ACC (\%) \\
\hline Conventional MRI & $85.0(17 / 20)$ & $94.0(32 / 34)$ & $89.5(17 / 19)$ & $91.4(32 / 35)$ & $90.7(49 / 54)$ \\
& {$[63.9-95.0]$} & {$[81.0-98.0]$} & {$[68.6-97.1]$} & {$[77.6-97.0]$} & {$[80.1-95.9]$} \\
Conventional MRI plus ADC value & $95.0(19 / 20)$ & $94.1 \%(32 / 34)$ & $90.5(19 / 21)$ & $96.9(32 / 33)$ & $94.4(51 / 54)$ \\
& {$[76.4-99.1]$} & {$[80.9-98.4]$} & {$[71.1-97.4]$} & {$[84.7-99.5]$} & {$[84.9-98.1]$} \\
\hline
\end{tabular}

Numbers in parentheses are the data used to calculate the percentages; Numbers in brackets are $95 \%$ confidence intervals; Conventional MRI includes T1WI, T2WI, contrast-enhanced MRI and DWI

mass filled with blood degradation products is characteristic MR imaging sign for OGCT [2, 9, 19]. We observed similar MRI appearances in 6 cases (Fig. 3). In our study, over $50 \%$ of OGCTs $(11 / 20)$ displayed high or mixed signal intensity on T1WI images, which may be related with the blood degradative components. Kim et al. reported that hemorrhage in the tumor was a common MRI finding in their seven cases [20]. This feature may be useful in discriminating OGCT from OSC since it is not noticed in the latter group. Regarding the lesion enhancement, 22 tumors examined in the present study showed mild (14/22, $63.6 \%)$ and moderate $(8 / 22,36.4 \%)$ enhancement relative to that of the myometrium. Avid and minor enhancement were not identified in OGCTs; while 4 SSTs noticed with avid enhancement and 12 fibromas and 4 fibrothecomas with minor enhancement. Although the enhancement type between OGCT and OSC did not differ significantly, it could be useful in discriminating them from broad ligament fibroids because the latter always show marked enhancement after injection of contrast medium.

Being a problem-solving modality, MRI could provide valuable information in differentiating malignant tumors from benign gynecological diseases. Numerous studies focusing on this issue have been reported with promising results $[15,21,22]$. In current study, MRI could well indicate the morphology and components of the OGCTs with an accuracy of approximately $90 \%$ in distinguishing OGCT from OSC. Four lesions were preoperatively misdiagnosed as fibroid (three lesions) and fibrothecoma (one lesion) because of either small size or homogeneous signal intensity. Pathological fluid (a large amount of ascites) was a rare condition in OGCT group (one case); however, it more often occur in OSC group (11 cases). The true mechanism is still unknown and may result from more estrogen secretion in the latter group. No lymphadenopathy was detected on MRI in all OGCT cases, which means it is a low potential malignant tumor unlike ovarian epithelial cancer. In one recent study, the authors also concluded that lymphadenectomy was not recommended in initial staging surgery of ovarian sex cord stromal tumor due to the low lymph node metastasis rate [23].

By displaying water molecule mobility (Brownian motion), DWI is considered as a functional imaging technique, permitting the quantitative evaluation of tumor tissues with ADC value. Theoretically, as a result of high cell densities and abundant cellular membranes, the movement of water molecule in cancer tissues is restricted on DWI images and then, the derived ADC value should be generally lower in malignant disease than in benign or healthy tissue [8, 24]. Many studies have reported ADC value could help to distinguish ovarian malignant lesions from benign conditions on both $1.5 \mathrm{~T}$ [25-27] and 3.0 T MR system [28, 29]. In one study, the authors reported that the mean ADC value of OGCT was $1000 \pm 120 \times 10^{-3} \mathrm{~s} / \mathrm{m}^{2}$ in their three cases with a $1.5 \mathrm{~T}$ MR machine using the same $b$ value [30], which is higher than our results $(817 \pm 144 \times$ $10^{-3} \mathrm{~s} / \mathrm{m}^{2}$ ). As for MR imaging, sometimes, OGCT need to be differentiated with fibrothecoma and ligamental myoma. Our results show that the mean ADC value of OGCT is lower than OSC with statistically significant difference. The similar results is not reported in previously published studies. However, owing to the limited reported cases, the comparative ADC value should be concluded in the large cohort data. If combining the ADC value, MRI yield a sensitivity of $95.0 \%$ and a specificity of $94.1 \%$ in diagnosis of OGCT, higher than with conventional MRI reading session alone. Our findings demonstrate that there is an overlap in the ADC value between OGCT and fibroma and fibrothecoma; however, there is no overlap observed between OGCT and SST. The possible reason may be that cystic changes often occur in the large tumor in both OGCT and fibrothecoma, resulting in a wide range of measurable $\mathrm{ADC}$ values.

There are several limitations to this study. First, we retrieved MR reports with suggested OGCT and OSC diagnosis on PACS system (within 6 years) and then, compared the MR results with pathological reports case by case. We do believe some cases may be missed for those not mentioned on MRI reports. So, the limited study samples in both OGCT and OSC group might have influenced the final results. Second, the ADC value was manually measured on the selected area based on individual habits. Standardization in measurement may influence the final results. Third, our study is based on 1.5 T MRI system while 3.0 T MRI has been used for a decade. Owing to the variable selected $b$ - value on DWI images and the limited case studies on $3.0 \mathrm{~T}$, we 
cannot compare the ADC value between these two modalities. However, for fibrothecoma, the mean ADC value do not differ with the results reported by our previous study with $3.0 \mathrm{~T}$ [31]. Studies with more OGCT samples on $3.0 \mathrm{~T}$ unit still be needed to determine the true differences in the future.

\section{Conclusion}

In conclusion, MRI could provide useful information in accurately diagnosing OGCT. The heterogeneous signal intensity on both T1WI and T2WI and high signal intensity on DWI images are more suggestive of OGCT diagnosis. ADC value might be useful in differentiating OGCT from OSC.

\section{Abbreviations}

ADC: Average diffusion coefficient; CT: Computed tomography; DWI: Diffusion weighted imaging; MRI: Magnetic resonance imaging; OGCT: Ovanrian granulosa cell tumor; OSC: Other sex-cord stromal tumor; T1WI: T1 weighted imaging; T2WI: T2 weighted imaging; US: Ultrasound

\section{Acknowledgements}

We would like to thank Mr. Jie He from the Department of Pathology, Obstetrics and Gynecology Hospital, Fudan University to provide the pathological picture in Fig. 3.

\section{Funding}

This work is financially supported by Shanghai Natural Science Funding grant (14ZR1404400) and Shanghai emerging advanced technology joint research project (SHDC12014130).

\section{Availability of data and materials}

The authors declare that all data supporting the findings of this study are available within the article.

\section{Authors' contributions}

$\mathrm{HZ}$ and GZ designed of the whole study; HZ, HYZ and SG performed the experiments and analyzed the data; $X L$ performed MRI scan; $Y Z$ did patient registration and patient care; $\mathrm{GZ}$ and $\mathrm{HZ}$ revised and wrote the manuscript finally. All authors read and approved the final manuscript.

\section{Ethics approval and consent to participate}

Our institutional review board approved the study, and the requirement for the informed consent of all participants was waived. In this article, institutiona review board was review board of obstetrics and gynecological hospital, Medical College, Fudan University.

\section{Consent for publication}

All authors read and approved the final manuscript. All authors agreed to submit this article.

\section{Competing interests}

The authors declare that they have no competing interests.

\section{Publisher's Note}

Springer Nature remains neutral with regard to jurisdictional claims in published maps and institutional affiliations.

\section{Author details}

'Department of Radiology, Obstetrics and Gynecology Hospital, Fudan University, Shanghai 200011, People's Republic of China. ${ }^{2}$ Department of Ultrasound, Daqing Oilfield General Hospital, Daqing, Heilongjiang Province 163001, People's Republic of China. ${ }^{3}$ Institute of functional and molecular medical imaging, Fudan University, Shanghai 200040, People's Republic of China
Received: 18 July 2017 Accepted: 20 May 2018

Published online: 05 June 2018

\section{References}

1. Jung SE, Rha SE, Lee JM, Park SY, Oh SN, Cho KS, et al. CT and MRI findings of sex cord-stromal tumor of the ovary. Am J Roentgenol. 2005;185(1):207-15.

2. Tanaka YO, Tsunoda H, Kitagawa Y, Ueno T, Yoshikawa H, Saida Y. Functioning ovarian tumors: direct and indirect findings at MR imaging. Radiographics. 2004:24(suppl 1):S147-S66.

3. Chen WW, Ruiz B, Killeen JL, Coté TR, Wu XC, Correa CN, et al. Pathology and classification of ovarian tumors. Cancer. 2003;97(S10):2631-42.

4. Cancer O. Version 1.2016, NCCN clinical practice guidelines in oncology J Natl Compr Cancer Netw. 2016;14:1134-63.

5. Seagle B-LL, Ann P, Butler S, Shahabi S. Ovarian granulosa cell tumor: a National Cancer Database study. Gynecol Oncol. 2017:46(2):285-91.

6. Ohara N, Kurachi O, Murao $\mathrm{S}$. Characteristics of magnetic resonance imaging findings of ovarian adult granulosa cell tumour. J Obstet Gynaecol. 2002:22(3):332-3.

7. Schultz KAP, Schneider DT, Pashankar F, Ross J, Frazier L. Management of Ovarian and Testicular sex Cord-stromal Tumors in children and adolescents. J Pediatr Hematol Oncol. 2012;34:S55-63. https://doi.org/10.1097/MPH. ob013e31824e3867.

8. Sala E, Rockall A, Rangarajan D, Kubik-Huch RA. The role of dynamic contrast-enhanced and diffusion weighted magnetic resonance imaging in the female pelvis. Eur J Radiol. 2010;76(3):367-85. https://doi.org/10.1016/j. ejrad.2010.01.026.

9. Morikawa K, Hatabu H, Togashi K, Kataoka ML, Mori T, Konishi J. Granulosa cell tumor of the ovary: MR findings. J Comput Assist Tomogr. 1997;21(6): $1001-4$

10. Yu S, Zhou X, Hou B, Tang BO, Hu JIE, He S. Metastasis of the liver with a granulosa cell tumor of the ovary: a case report. Oncol Lett. 2015;9(2):816-8.

11. Anandpara KM, Aswani Y, Thakkar H, Hira P, Sathe PA. Juvenile granulosa cell tumour of the ovary with Unilocular pure cystic presentation: a case report and review of literature. Pol J Radiol. 2016;81:120-4.

12. Rusterholz KR, MacDonald W. An unusual case of juvenile granulosa cell tumor of the ovary. Radiology Case Reports. 2009;4(1):178.

13. Cheong M-L, Shen J, Huang S-H, Chien T-Y. Long-term survival in a patient with an advanced ovarian juvenile granulosa cell tumor with Para-aortic lymph node metastasis. Taiwanese Journal of Obstetrics and Gynecology. 2016;55(6):907-9.

14. Grab D, Flock F, Stöhr I, Nüssle K, Rieber A, Fenchel S, et al. Classification of asymptomatic adnexal masses by ultrasound, magnetic resonance imaging, and positron emission tomography. Gynecol Oncol. 2000;77(3):454-9.

15. Sohaib SAA, Sahdev A, Trappen PV, Jacobs IJ, Reznek RH. Characterization of adnexal mass lesions on MR imaging. Am J Roentgenol. 2003;180(5):1297-304.

16. Rajkotia K, Veeramani M, Macura KJ. Magnetic resonance imaging of adnexal masses. Top Magn Reson Imaging. 2006;17(6):379-97. https://doi. org/10.1097/RMR.0b013e3180417d8e.

17. SHAABAN A, REZVANI M. Ovarian Cancer: detection and radiologic staging Clin Obstet Gynecol. 2009:52(1):73-93. https://doi.org/10.1097/GRF. Ob013e3181961625.

18. Tanaka YO, Ide Y, Nishida M, Nishide K, Tsunoda H, Kajitani M, et al. Ovarian tumor with functioning stroma. Comput Med Imaging Graph. 2002;26(3):193-7.

19. Horta M, Cunha TM. Sex cord-stromal tumors of the ovary: a comprehensive review and update for radiologists. Diagn Interv Radiol. 2015;21(4):277-86.

20. Kim SH, Kim SH. Granulosa cell tumor of the ovary: common findings and unusual appearances on CT and MR. J Comput Assist Tomogr. 2002;26(5): $756-61$

21. Zhang H, Zhang G-F, He Z-Y, Li Z-Y, Zhang G-X. Prospective evaluation of 3T MRI findings for primary adnexal lesions and comparison with the final histological diagnosis. Arch Gynecol Obstet. 2014;289(2):357-64.

22. Thomassin-Naggara I, Toussaint I, Perrot N. Characterization of complex adnexal masses: value of adding perfusion- and diffusion-weighted MR imaging to conventional MR imaging. Radiology. 2011;258(3):793-803. https://doi.org/10.1148/radiol.10100751.

23. Cheng H, Peng J, Yang Z, Zhang G. Prognostic significance of lymphadenectomyin malignant ovarian sex cord stromal tumor: a retrospective cohort study and meta-analysis. Gynecol Oncol. 2018; 148(1):91-96. https://doi.org/10.1016/j.ygyno.2017.10.022.

24. Levy A, Medjhoul A, Caramella C, Zareski E, Berges O, Chargari C, et al. Interest of diffusion-weighted echo-planar MR imaging and apparent 
diffusion coefficient mapping in gynecological malignancies: a review. J Magn Reson Imaging. 2011;33(5):1020-7.

25. Punwani S. Diffusion weighted imaging of female pelvic cancers: concepts and clinical applications. Eur J Radiol. 2011;78(1):21-9. https://doi.org/10. 1016/j.ejrad.2010.07.028.

26. Takeuchi M, Matsuzaki K, Nishitani H. Diffusion-weighted magnetic resonance imaging of ovarian tumors: differentiation of benign and malignant solid components of ovarian masses. J Comput Assist Tomogr. 2010;34(2):173-6.

27. Yin B, Li W, Cui Y, Chu C, Ding M, Chen J, et al. Value of diffusion-weighted imaging combined with conventional magnetic resonance imaging in the diagnosis of thecomas/fibrothecomas and their differential diagnosis with malignant pelvic solid tumors. World Journal of Surgical Oncology. 2016;14:1-5.

28. Zhang H, Zhang G-F, He Z-Y, Li Z-Y, Zhu M, Zhang G-X. Evaluation of primary adnexal masses by 3 T MRl: categorization with conventional MR imaging and diffusion-weighted imaging. Journal of Ovarian Research. 2012;5(1):33.

29. Uehara T, Takahama J, Marugami N, Takahashi A, Takewa M, Itoh T, et al. Visualization of ovarian tumors using 3T MR imaging: diagnostic effectiveness and difficulties. Magn Reson Med Sci. 2012;11(3):171-8.

30. Bakir B, Bakan S, Tunaci M, Bakir VL, lyibozkurt AC, Berkman S, et al. Diffusionweighted imaging of solid or predominantly solid gynaecological adnexial masses: is it useful in the differential diagnosis? Br J Radiol. 2011;84(1003):600-11.

31. Zhang H, Zhang GF, Wang TP, Zhang H. Value of 3.0 T diffusion-weighted imaging in discriminating thecoma and fibrothecoma from other adnexal solid masses. J Ovarian Res. 2013;6:58

Ready to submit your research? Choose BMC and benefit from:

- fast, convenient online submission

- thorough peer review by experienced researchers in your field

- rapid publication on acceptance

- support for research data, including large and complex data types

- gold Open Access which fosters wider collaboration and increased citations

- maximum visibility for your research: over $100 \mathrm{M}$ website views per year

At BMC, research is always in progress.

Learn more biomedcentral.com/submissions 